\title{
Building Information Modelling in Agile Environments - an Example of Event Management at the Airport of Tempelhof
}

\author{
Zsuzsa Besenyöi ${ }^{*}$, Markus Krämer and Faraz Husain \\ Hochschule für Technik und Wirtschaft Berlin, Department II. Ingenieurwissenschaften - Technik \\ und Leben, 12459 Berlin, Germany
}

\begin{abstract}
The concept of Building Information Modelling (BIM) is heavily promoted but rarely used in the Facility Management (FM) industry. Especially for event locations, where FM and Event Management organizations have to collaborate within a short period in a highly flexible manner with various external partners and public authorities. Hence, applying the method of BIM for Event Management is even more difficult compared to regular building operations. As a first attempt to dissolve this issue, the presented article emphasizes on the adoption of agile project management framework for BIM-based Event Management, where the focus lays on the creation of a suitable Building Information Model (BIM Model), at one hand for general FM, on the other hand for event management purposes. The paper shows results of a collaborative research project BIM4Events founded by KiraDIGI between the HTW Berlin, Berlin Airport of Tempelhof and Metropolia UAS Helsinki, as a Scrumbased BIM Model development at the case of a public event, 'Sommerfest - Tag der offenen Tür', organized in September 2018.
\end{abstract}

\section{Introduction}

Building Information Modelling is an emerging technology and process that facilitates digital representation, exchange, use and reuse of all pertinent information about the life cycle of a building or facility from planning, design, construction, operations, and to the ultimate disposal [1].

From building operation and moreover FM perspective, the BIM Model is the digital twin of the existing building, which constantly represents the as-it-is now lay-out, appearance and characteristic of the given structure. Considering the purpose of the BIM Model, besides it serves as a communication platform between the different stakeholders, it functions as a single source of truth, providing continuously up-dated building-related information in order to support different FM-related application scenarios [2]. Besides visualization of local situations in the building for service and maintenance staff, which are not familiar with the building, making use of digital building models for simulations of

\footnotetext{
Corresponding author: Zsuzsa.Besenyoei@HTW-Berlin.de
} 
space usage and energy efficiency or checking compliance of regulatory issues comes into focus of FM organizations.

Despite of these benefits, till nowadays most of the BIM projects in research, industry or of public authorities have focused on the planning, design and the construction stages, thus BIM for FM is still an emerging area and there is still limited knowledge available on the subject $[3,4]$. The authors believe that, one of the main problems to implement BIM in the operation sector (since till now only a couple of percentage of the existing buildings possess a digital twin), is the un-clarified Building Information Modelling aspect. Within this concern, four key challenges were identified, namely how the development of the "AsBuilt" BIM Model should be managed in respect of the information needs, information transfer, level of effort of creating the BIM Model and handling available but uncertain building data [5].

Nowadays events and the event environment become more and more complex [6], mainly in terms of security, acoustic and lighting requirement as well as media supply [7]. Considering event management as an industry, which is utilizing a building or a built environment, event organizers can be seen as a sub-division of the Facility Management team, regardless of the actual legal binding agreements of the event project. Nonetheless, cooperation of various specialist disciplines, public authorities and other stakeholders is already challenging in regular operations, within event production workflows have to be accelerated, offering quick response times and fast information delivery. In order to provide a systematic methodology, event management is turning towards project management, thus possessing project-character and require their own management for target-oriented and professional design $[6,8]$. Based on the developments in event management described here, it is obvious that evaluating the benefits of BIM based collaboration in this field is a promising approach.

In this article events are treated as kind of a 'unique building project in itself' and has fixed yet short lifecycle (Plan, Construct, Operate, Demolish) and with it comes specific requirement set, use cases, meanwhile the building which is the event location remains the same. Thus, considering one special event and its related requirements, as a simplified, short-term, but repetitive construction project, which always occurs in the same location, the further development and utilization of an already exiting BIM Model made for general FM purposes can be advantageous (see Fig. 1.). Furthermore, taking into account the fact, events are organized repetitive (annually) in the same location, in which the requirements have slight changes compared to the previous event, the BIM Model, used as a repository model made for the initial event, could be adopted using slight adjusting actions.

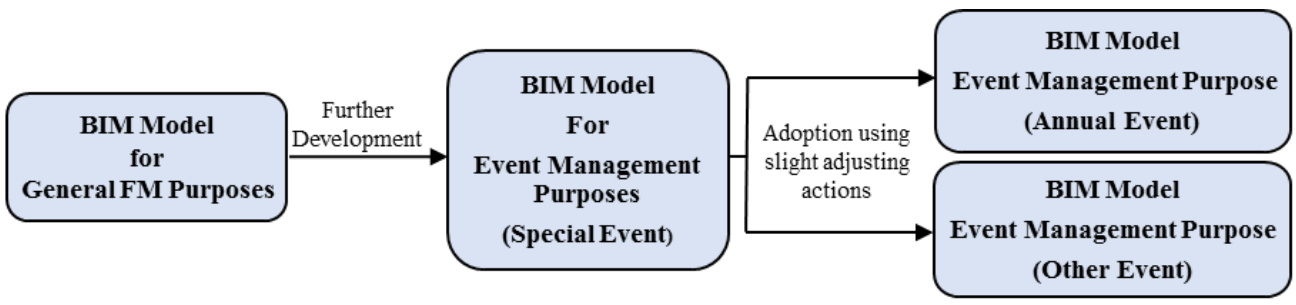

Fig. 1. BIM Model development for Event Management purposes

The main purpose of the current article is to attempt to define and apply a usable framework at one hand to overcome the identified challenges of the BIM Model development for general FM purposes, on the other hand to provide a clear understanding about how this model further development, utilization (and adoption) should occur effectively, in order to support different event management use cases. The authors believe that, due to the un-defined scope of such a project, the BIM Model development for FM as 
well as for event management purposes should be planned and executed by agile project management frameworks, rather by traditional project management methodologies.

As a validation, the paper shows results of a collaborative research project BIM4Events founded by KiraDIGI between the HTW Berlin, Berlin Airport of Tempelhof and Metropolia UAS Helsinki, as a Scrum-based BIM Model development at the case of a public event, 'Sommerfest - Tag der offenen Tür', organized in September 2018.

\section{Agile Project Management in Building Information Modelling}

Traditional project management or Waterfall methodology is a well-known path within the building industry, which defines sequence of phases to be completed whole along the project. Within this approach the activities only can move to the next phase once the previous one has been completed and verified [9]. This methdology is relevant and applicable to all projects, where the project scope, the time and cost associated in delivering that scope, are fixed and relatively stable at the earliest possible opportunity [10].

However, when constant modifications of the project specification coupled with occurring problems in defining the original product requirement arise, cost overruns and schedule delay occurs as well as the product quality declines [11]. There is an argument from the side of researchers, like [9,11-13] whether the practice of traditional project management is not always the most adequate methodology within the building sector.

Furthermore, traditional project management methodology is preferable for projects in which the outputs are physical objects (such as construction projects, hardware installation projects, etc.) [9], however at the case of software development (i.a. digital products), agile projects are three times more successful than waterfall projects [13].

Agile thinking, production and project management has evolved since 1990 and has made a significant headway in the information systems industry [12]. From the viewpoint of agile project management, agility means the ability to both create and respond to change in order to profit in a turbulent business environment [14]. Hence agile methodologies allow for changing requirements (scope) over time, by using cross-functional teams incorporating planners, designers, developers and testers - which work on successive iterations of the product over fixed time periods [15].

Till nowadays couple of successful attempts have appeared to adopt agile project management to the construction industry, especially at the case of Building Information Modelling. For instance, [16] shows an executed synthesis of the Agile and BIM features making use of the digital representation of the building within BIM methodology, which makes applying agile concepts much easier. Consequently, they generally integrate and commonly apply the benefits of the two concepts. [13] represents a theoretical framework for using agile project management, BIM, and iterative design to achieve improved building performance. Lastly [17] adopts and implies agile project management features, like 'Sprint', for BIM Model development throughout the project life-cycle.

Scrum is one of the many agile project management frameworks, that has been used to manage complex product, development since the early 1990s [18]. In general, the use of Scrum has proven to be very valuable in complex projects, especially those where the requirements and/or the vital technology are not yet very mature, and it is, amongst all the different agile methods (e.g., Extreme Programming, Adaptive Project Management, Dynamic Project Management), the one most frequently used [11].

The Scrum framework consists of the Scrum Roles, the Scrum Artefacts and the Scrum Events, as it can be seen in Fig. 2., which detailed explanation can be seen in the following resources $[11,14,18]$. 


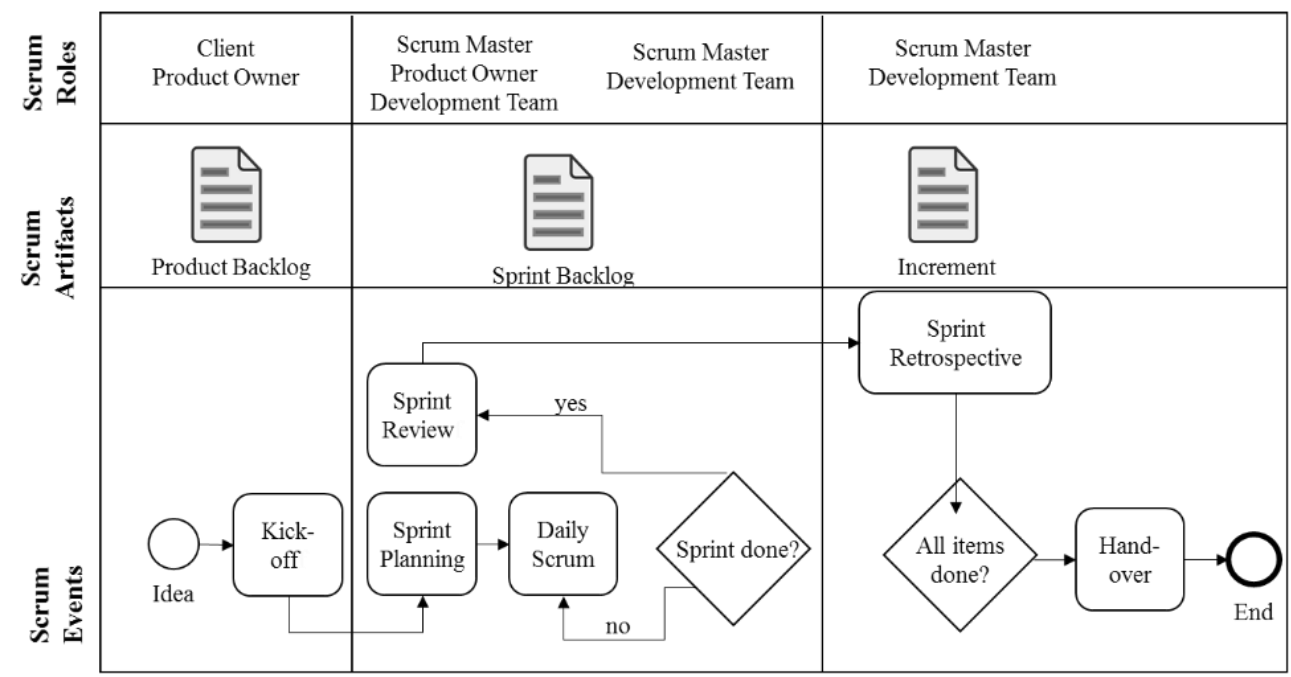

Fig. 2. Typical Scrum Framework [11]

Till now, there has been few numbers of attempts in the academic field, like [11], to imply this process framework in the construction industry, moreover as the [19] has reported, there are already real case projects, where it was implemented successfully especially at the case of Building Information Modelling.

\section{Adoption of Agile frameworks into BIM Model development for Event Management}

Based on the presented literatures, BIM Model development can be successfully planned and managed by agile project management frameworks throughout a project life-cycle. Accordingly, the aim of the current chapter is to attempt to describe two generalized agile featured workflows for BIM Model creation, firstly for general FM purposes (see Fig. 3.), since there is still not a clear approach how to establish such a digital product. Secondly, the presented process will be adopted for BIM Model development from the perspective of Event Management (see Fig. 4.), where it is assumed an adequate BIM-FM Model is already established, ready to be further developed.

As a validation, the two agile featured frameworks will be commonly applied in Chapter 4. in a form of a Scrum-based BIM Model development at the case of a public event, 'Sommerfest - Tag der offenen Tür', organized in September 2018 at the Tempelhof Airport, Berlin.

As an initial point for the BIM Model development for event management, firstly an 'As-built' BIM Model for general FM purposes must be developed (see Figure 3.). To do so, essentially pre-determined BIM-FM use cases have to be established and prioritized. According to the settled hierarchy, the mandatory building information (i.a. information, which must be included inside the BIM Model) has to be identified and collected, firstly for the highest priority use case. The collection of these required data can occur in two ways. At one hand, according to the available 2D CAD drawings and CAFM systems (collection of available building information), on the other hand by on-sight manual or automatic (e.g. 3D Laser Scanning) surveying (collection of unavailable building information, see [4]). If the compilation of the required data is finished, then their validation must occur, in order to ensure the up-to-dateness (available information) and adequate form (unavailable information) of these data. If this validation leads to a false end, then the data, which are 
not current, has to be identified as unavailable information, that has to be re-collected. At the case of inadequate form, the process of these data must be executed, in an iterative way, in order to gain adequate building information. According to these examined information pile, the development and utilization of the BIM Model for the selected FM use case can be executed by one of the preferred BIM authoritative tools.

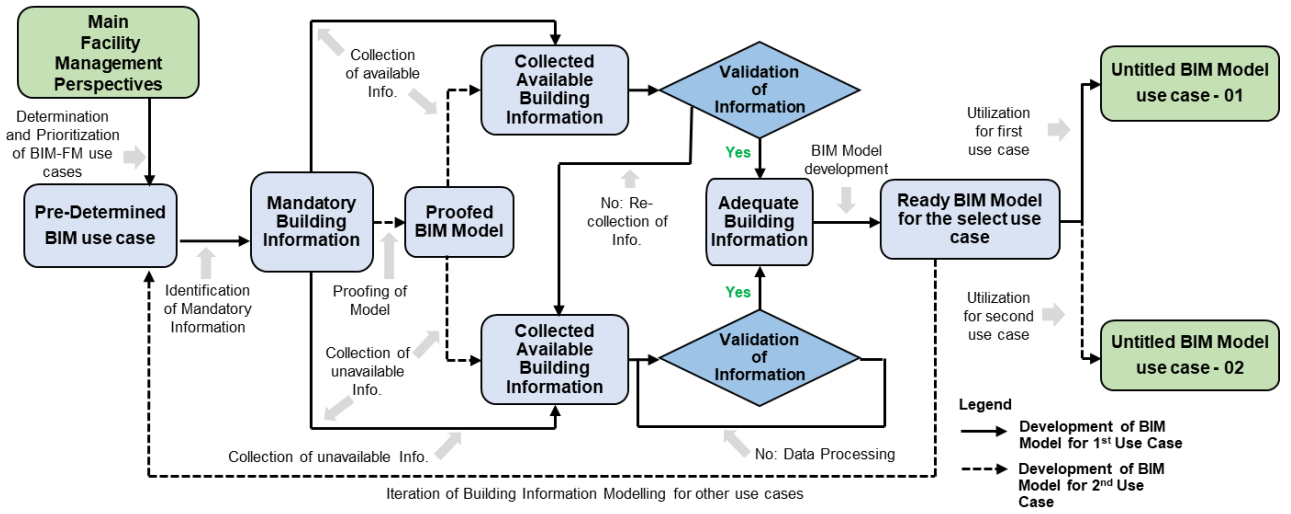

Fig. 3. Workflow of BIM Model development from the perspective of Facility Management

If the so prepared BIM Model is wished to be utilized for other FM use cases possessing lower priorities, then the above-mentioned procedure has to be iteratively executed. During these cycles, it is crucial to prove, whether the mandatory building information has already been included (in the right form) inside the BIM Model, avoiding unnecessary building data collection and building modelling (at this point, it is assumed the already prepared BIM Model is adequately maintained in accordance with the real-life changes). According to this examination, the identified missing information has to be collected and validated in the above mentioned two ways, furthermore built-in during the BIM Model creation.

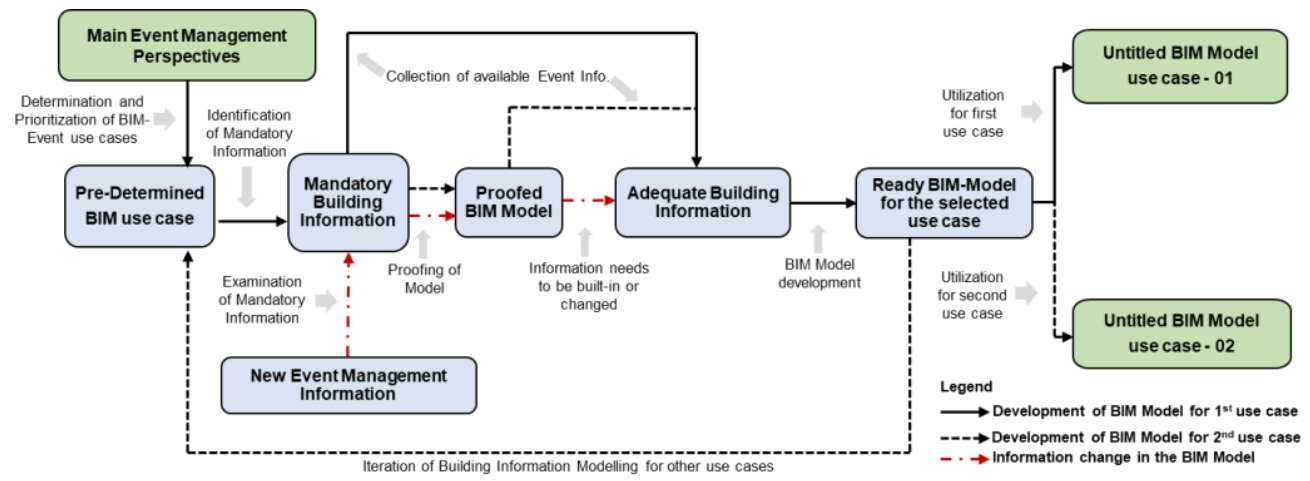

Fig. 4. Workflow of BIM Model development from the perspective of Event Management

According to the presented framework for BIM Model development for general FM purposes, its adoption to BIM Model development for event management purposes has been established (see Fig. 4.). At the current case, the significant BIM-Event use cases have to be also gathered and prioritized, accordingly the mandatory building information has to be identified for the most significant use case firstly. At this point, if the BIM-FM Model actually represents the 'as-it-is-now' lay-out of the building, meaning it contains all the previously identified unavailable information during the BIM-FM Model development, then only the 'collection of available event information' (e.g.: required number, size and location of the stages and/or tents, etc.) is necessary. Assuming the BIM-FM Model possess such a quality, the collected information can be instantly identified as adequate building 
information, ready to be modelled. Compared to the BIM-FM framework, the validation of this information is dismissed here, since the incoming event management information are always up-to-date.

However, as it has been mentioned, events can be considered as shorten up construction projects, where constant modifications of the project requirements coupled with occurring problems in defining the original product requirement might occur. Therefore, when such a case arises, the incoming information firstly has to be examined whether it is a mandatory building information, namely the received information has to be included inside the BIM Model or not. Then the BIM Model should be proved, if the information is included and upto-date. If this examination leads to a negative answer, namely the BIM-Model does not contain the required data or it is included, but not in an up-to-date form, then the incoming information can be considered instantly as an adequate building information, ready to be modelled or changed inside the BIM Model.

As it was the case of the BIM Model creation for general FM purposes, the iterative execution of this process is necessary for the lower priority use cases. Consistently, the mandatory information has to be also identified, and proved whether it has been already added to the BIM Model. If not, their data collection is necessary and the above-mentioned procedure at the first use case has to be followed.

\section{Case Study at the airport of Tempelhof}

The current case study shows results of a collaborative research project, BIM4Events founded by KiraDIGI, between the HTW Berlin, Berlin Airport of Tempelhof and Metropolia UAS Helsinki, that has been started on the beginning of April 2018, continuously running for eight months. The main target of the research project is a BIM Model development for event management purposes, in order to test different event related application scenarios.

As a pilot, a one-day public event has been selected, namely the 'Sommerfest - Tag der offenen Tür', organized on the 1. September 2018 at the Tempelhof Airport (see Fig. 5.). Altogether around 50.000 visitors were expected during this opened exhibition, where the visitors could gain an insight look into the 'Vorfeld' (Pre-field), Hangar 4, the former transit zone as well as the Main Departure Hall. In the designated areas, beside numerous amounts of exhibitors have appeared to provide information about their relations to the Tempelhof Airport itself, various types of entertainment and culinary stages/tents were established assuring the public adequate enjoyment.

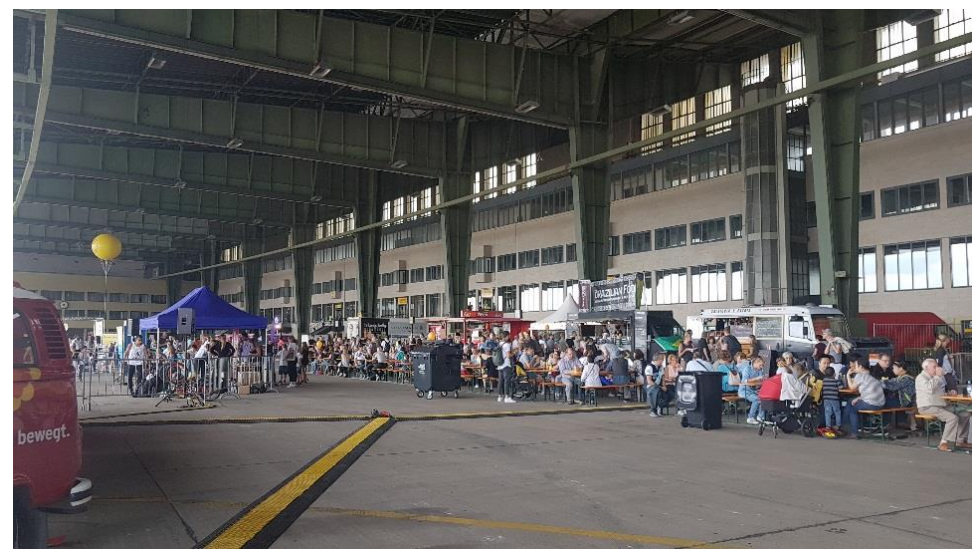

Fig. 5. Vorfeld (Pre-field) during the 'Tag der offenen Tür' in 2018, September 
The original project plan for the research project (see Fig. 6.), which was based on traditional project management methodologies, turned out to be ineffective, because of the high level of uncertainty in terms of use cases to be defined within the project scope. Thus, the initial project plan was revised by applying the above described two agile featured frameworks, in order to dissolve these obstacles.
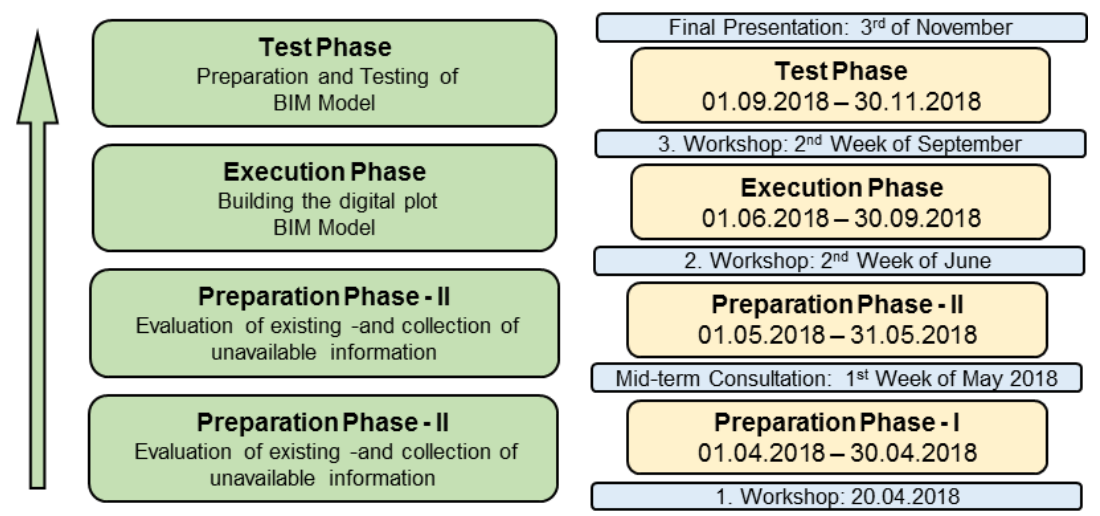

Fig. 6. Original project plan of the KiraDIGI research project

To provide a systematic approach, a Scrum-based BIM development had been established, based on the above presented agile frameworks, providing the final project plan for the research project (see Fig. 7.).

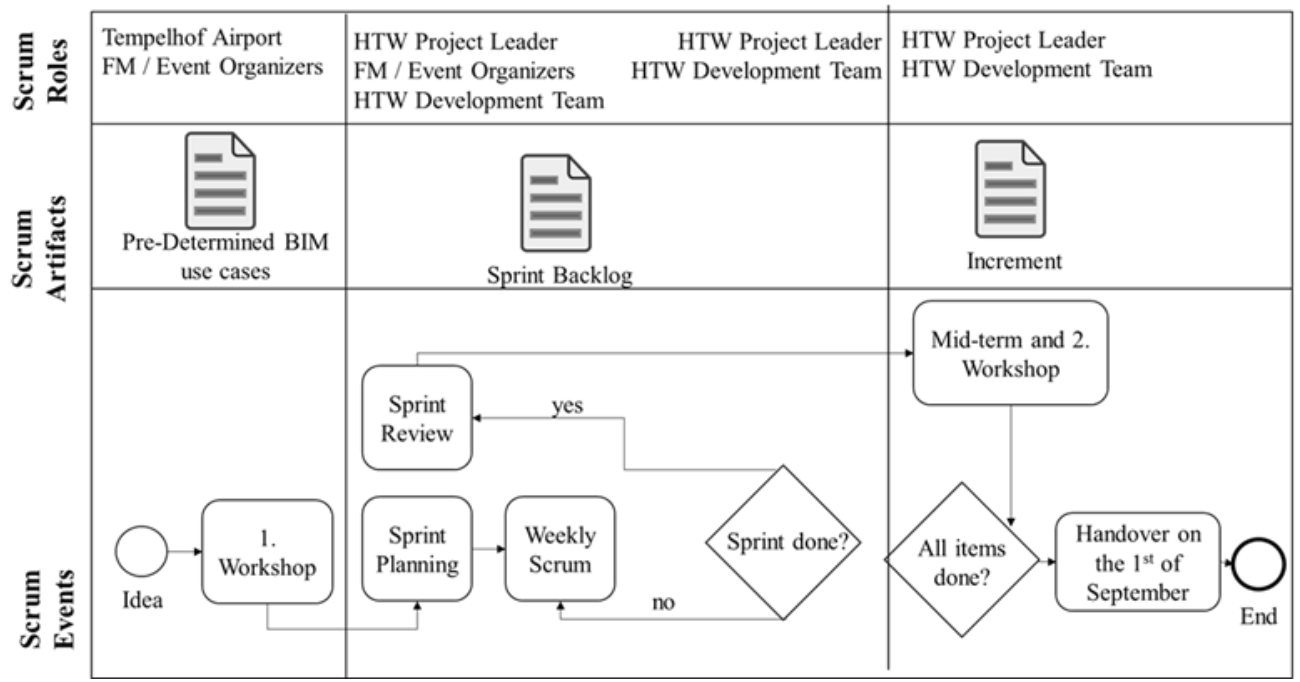

Fig. 7. Final Scrum-based project plan for the KiraDIGI research project

Going along the Scrum framework, the product backlog essentially defines the targeted FM/event management use cases ensuring the deliverable product usability at the end.

The client in authors' case study is the Berlin Tempelhof Airport Project Authority, meanwhile the product owner is its subsidiary FM and Event Management department. In the case study, scrum master was akin to the HTW Project Leader to control and coordinate the project and the scrum team (HTW Development Team) had multiple actors and it did not have a strict hierarchy. This team focused on collaboration and was open to changes with addition of members with development of the uses cases during the project lifecycle.

Considering the time frame of the project, the sprints were organized in the way of fulfilling the BIM Model development and couple of the selected utilization scenarios till 
the $1^{\text {st }}$ of September 2018. As a Kick-off, the initial 1. Workshop was identified, meanwhile the Sprint retrospectives were identical with the originally defined Mid-term and 2. Workshop. Despite of the classical daily scrum meetings, weekly scrum events were held during the project, due to the small number of participants of the development team.

In this research, the first sprint was considered as the general identification of the possible BIM use case scenarios, beside the selection of two smaller exhibition areas (Main Departure Hall and a smaller former office unite in the Hangar 4.). According to the selected locations, the identification of the relevant FM use cases could have been started. For both cases, the main FM use case was to obtain the as-it-is now layout, beside an extra scenario at the case of the Main Departure Hall, namely the real-life visualization. Considering the BIM-Event use cases, their identification occurred according to the interests of both parties (useful and applicable use case scenario(s)) and the possibility of re-using the results of the research project for the next year up-coming event(s). In this phase the increment was the gathered and evaluated BIM event use cases, which could be considered as a necessary, but minor part of the final digital model.

With the product backlog available, this phase had new set of objectives to gather the available and unavailable building information in such as building plans, point cloud data bases and data from building operator. The increment in this cycle lead focused on gathering and validating the CAD plans and the point cloud data base, whether they are in an adequate form.

The third sprint was planned the following month in which all data was collated and proofed from plans and points clouds. In this phase, the main focus laid on the data processing originating from the point cloud data base. As the first real digital increment of the Scrum process, the checked, registered and segmented point-cloud data (see Fig. 8.) was delivered into the BIM authoritative tool (at the present case, into Autodesk Revit 2017), ready to be used for the BIM modelling.

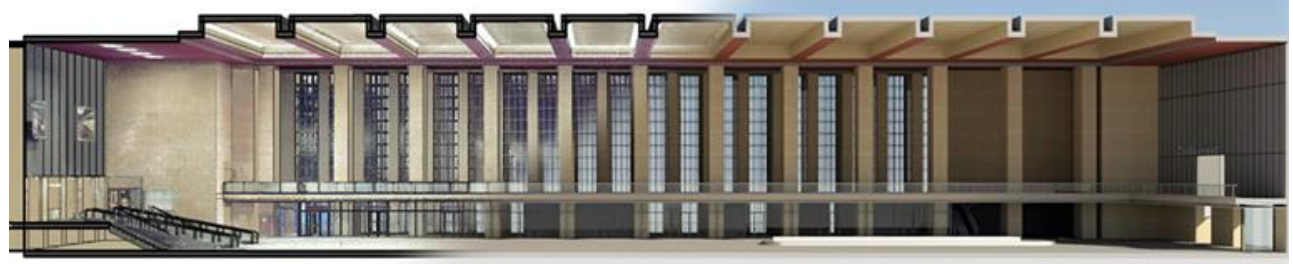

Fig. 8. Main Departure Hall, as the registered point cloud (left side) overlapping the texturized BIM Model (right side)

Following the previous sprint, the fourth sprint had two internal cycles. Within the first phases, the main task was to develop a basic building shell using the gathered point cloud data and CAD plans to obtain the as-it-is now layout of the Main Departure Hall and at the second phase for the smaller office unit. The scrum-master and the scrum-team provided additional input at this change and the end of this sprint cycles leads to the incremental products, which are the BIM-FM Models, ready to be further developed for the purpose of event management.

The fifth and the final sprint cycle in authors research was tasked to prioritize the previously identified event use cases at both locations. At the case of the Main Departure Hall, the application of Virtual Reality (VR), meanwhile at the case of the office unit the exhibition arrangement was identified. However, firstly the task to add-in details, like texturing for visual conformity to Main Departure Hall, as the previously identified second FM use case had to be executed (see Fig. 8.). Therefore, the VR use case could not have been fulfilled, thus had to be postponed for the next sprint. At the case of the former office 
unite, the BIM Model is further refined using inputs and directions from the Project Tempelhof Team. The Development Team modelled 'parametric objects' for exhibit stand and then placed it in the BIM Model (see Fig. 9.). This additive iteration thus leads an enhanced product, and in our case study, a final product that is a 'BIM Model with Exhibition Stand' which fulfils the objective to demonstrate use of BIM for event management purposes.
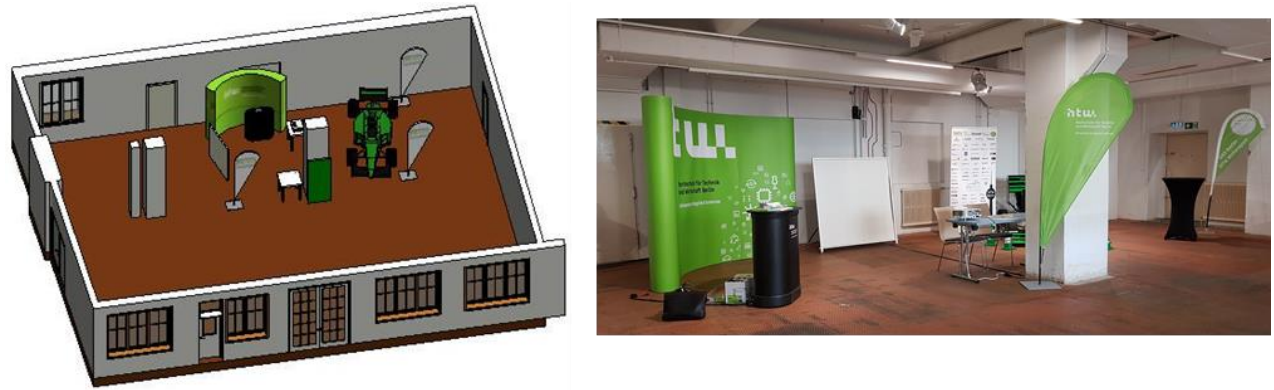

Fig. 9. BIM-Event Model for the purpose of exhibition arrangement and in the reality on the pilot event

This presented BIM model will be used in VR Visualisation as the next coming lower priority use cases in the following up-coming sprint.

\section{Conclusion}

Despite of its clear benefits, the concept of Building Information Modelling is rarely used in the Facility Management industry. Among other problems, the un-clarified Building Information Modelling aspect for existing buildings, possessing no BIM Model has been identified as the main issue. Considering event management as an industry, which is utilizing a building or a built environment, event organizers can be seen as the sub-division of the Facility Management team. Nonetheless, event management is turning towards project management, and require their own management for target-oriented and professional design, thus the further development of a BIM-FM Model for event purposes has great potentials.

However, till nowadays there are only a few existing buildings possess a BIM Model for general FM purposes, moreover there is no clear understanding about how its further development should happen effectively in order to support different event management use cases.

Therefore, the authors have established two agile featured frameworks, at one hand for creating a general BIM-FM Model, on the other hand to further develop this model for the purpose of event management. The biggest advantage of these frameworks is to provide a way of continuous and iterative improvement of the BIM Model and allows changes of scope and specification more easy than it can be done using traditional project management methods. As a validation, the two agile featured frameworks were successfully applied as a Scrum-based BIM Model development at the case of the public event 'Sommerfest - Tag der offenen Tür', organized in September 2018 at the Tempelhof Airport, Berlin.

The utilization of the featured frameworks for BIM based event management itself seems to be a very promising approach, enabling the model development process to become more flexible for un-expected changes. Considering the limitation of the presented article, certain parts, like its iterative feature for secondary event use cases as well as the created BIM-event Model incremental adaption were not validated within the scope of this article. 


\section{References}

1. Nepal, M. P. and Staub-French, S. (2016) Supporting knowledge-intensive construction management tasks in BIM, Journal of Information Technology in Construction (ITcon), 21 (March), pp. 14.

2. Aengenvoort, K. and Krämer, M. BIM in the Operation of Buildings, In: Borrmann, A. et al., Building Information Modeling, Technology Foundations and Industry Practice, pp. 477-491.

3. Kelly, G. et al. (2013) BIM for facility management : a review and a case study investigating the value and challenges, Proceedings of the 13th International Conference on Construction Applications of Virtual Reality, 30-31 October 2013, London, UK, pp. 191.

4. Krämer, M. and Besenyoi, Z. (2018) Towards Digitalization of Building Operations with BIM, in IOP Conference Series: Materials Science and Engineering. pp. 2

5. McArthur, J. J. (2015) A Building Information Management (BIM) Framework and Supporting Case Study for Existing Building Operations, Maintenance and Sustainability, Procedia Engineering. Elsevier B.V., 118, pp. 1104.

6. O'Toole, W. (2000) Towards the integration of Event Management Best Practice by the Project Management Process, Events beyond 2000 : Setting the Agenda ; Proceedings of Conference on Event Evaluation, Research and Education, July 2000, Sydney, pp. 86-92.

7. Sakschewski, T. and Siegfried P. (2017) Veranstaltungsmanagement: Märkte, Aufgaben und Akteure, pp. Vorort V.

8. Thomas, O., Hermes, B. and Loos, P. (2008) Reference Model-Based Event Management, International Journal of Event Management Research, 4(1), pp. 46.

9. Al-zwainy, F. M. S., Mohammed, I. A. and Raheem, S. H. (2016) Application Project Management Methodology in Construction Sector: Review, 7(3), pp. 244-253.

10. Project Management Institute (2013) A Guide to the Project Management Body of Knowledge, 5, pp. 44.

11. Streule, T. et al. (2016) Implementation of Scrum in the Construction Industry, Procedia Engineering, 164 (June), pp. 269-276.

12. Owen, R. L. and Koskela, L. (2006) Agile construction project management, 6th International Postgraduate Research Conference in the Built and Human Environment, pp. 22-33.

13. Sakikhales, M. H. and Stravoravdis, S. (2017) Building Information Modelling, Building Performance, Design and Smart Construction, pp. 69

14. Highsmith, J. (2002) Agile Software Development Ecosystems, pp.16, pp. 133-137.

15. Bowes, J. (2014) Agile vs Waterfall : Comparing project management methods', Manifesto.co.uk - Agile Delivery, Available at: https://manifesto.co.uk/agile-vswaterfall-comparing-project-management-methodologies/.

16. Tomek, R. and Kalinichuk, S. (2015) Agile PM and BIM: A Hybrid Scheduling Approach for a Technological Construction Project, Procedia Engineering. Elsevier B.V., 123, pp. 557-564.

17. Kumar, S. S. and McArthur, J. J. (2015) Streamlining Building Information Model Creation Using Agile Project Management, WIT Transactions on the Built Environment, 149, pp. 229-240.

18. Schwaber, K. and Sutherland, J. (2013) The Scrum Guide, Scrum.Org and ScrumInc, (July), pp. 17.

19. pom+Consulting AG (2017) Concrete goes agile, PMI-Switzerland Chapter, SCRUM and BIM, 14. November 2017 Switzerland, Zurich, pp. 1-56. 